\title{
The Effectiveness of CCMPedia in Teaching and Learning Calculus
}

\author{
Rusnani Mohamad KHALID ${ }^{1, a}$, Shamsatun Nahar AHMAD ${ }^{1, b}$ and Mohd Hanafi \\ Azman $\mathrm{ONG}^{1, \mathrm{c}}$ \\ ${ }^{1}$ Universiti Teknologi MARA Cawangan Johor, Malaysia \\ arusna162@johor.uitm.edu.my, bshams551@johor.uitm.edu.my, 'cnapieong@uitm.edu.my
}

Keywords: CCMPedia, Calculus, Mixed Design, Teaching and Learning

\begin{abstract}
Calculus is one of the main courses for the students of Science, Technology, Engineering and Mathematics (STEM) at tertiary level. Thus, all students who are currently taking this course need to get at least grade $C$ for them to pass the examination. Many educators used to apply tools in their teaching method to make the students understand clearly on the topics given in their syllabus. However, it is very seldom that the effectiveness of the tools being examined. In this paper, the effectiveness of integrating CCMPedia in teaching and learning Calculus 1 is discussed. CCMPedia is an encyclopedia for common calculus mistakes, which was designed by some educators from Universiti Teknologi MARA, Johor branch, Malaysia (UiTMJ). By using experimental method, four classes were divided into control group and experimental group. The questions were designed according to pre-knowledge, basic knowledge and Calculus 1. Data was collected from 88 students and the result was analyzed by mixed design analysis to access the effect of time factors between pre-test and post-test and the group effects between control and experimental groups. CCMPedia is found to be one of the good mechanisms to assist students in learning process, particularly in basic knowledge and Calculus 1.
\end{abstract}

\section{Introduction}

Nowadays, teaching and learning mathematics has become more challenging, particularly in getting students' engagement in classroom. The engagement of students in every course of mathematics at university level is very essential for them to understand each topic that has been taught because mathematics is cumulative, that is, it creates an internally coherent structure and some concepts are built based on other concepts. Hence, small gap in knowledge creates further misconceptions that are built one upon another, and which after some time are revealed in an error avalanche. Mathematics also called hierarchical build-up of concepts that must be woven together, skills and facts by Sarwadi and Shahril for the successful learners of mathematics [1]. An unrevealed error, which is rooted in the mind of students, is therefore a major threat to the construction of students' mathematical knowledge [2]. Meanwhile, student errors may reveal the erroneous problem-solving process and thus provide information on the understanding of and the attitudes towards mathematical problems [1]. To overcome the problem in understanding the knowledge of mathematics and misconception, changing in the method of teaching should be considered. One of the changes is by integrating suitable tools in the teaching process due to the reasons that teaching mathematics which was integrated with certain tools and methods give more advantages for the students to understand better at many levels $[3,4,5]$. In line with the benefit of using tools in teaching and learning, research on the effectiveness in using the appropriate tool must be carried out.

Calculus is a branch of mathematics and one of the main courses for Science, Technology, Engineering and Mathematics (STEM) students where they must possess at least grade C in order to pass the examination. All educators who are teaching calculus know that previous related concepts like the concept of a variable and the concept of function are necessary for the students to understand the calculus concepts. However, the learning of calculus includes new notions like the notion of limit, differentiation and integration which intrinsically contain changing quantities. Moreover, the differential and integral calculus are based upon the fundamental concept of limit. Clearly, those elements reveal to the understanding of calculus concept and lead to good performance in 
examination. Consequently, preliminary research by [6] to Universiti Teknologi MARA, Johor branch, Malaysia (UiTMJ) students taking Calculus 1, has found that the only factor influences students' performance is self-effort. Therefore, the attitudes of the students in learning mathematics influence their understanding in concept, principle and practices [5]. Thus, this study is carried out to help the students in reducing the misconceptions as well as increasing students' understanding in learning Calculus 1 by integrating a tool namely CCMPedia in teaching Calculus 1.

There are variety of tools used to improve the techniques of teaching in mathematics, for example by using technology, ICT in teaching secondary school [7], GetTheMath, relate algebra to real world [8], and visual approach [9,10] in the topic of continuity and able to raise up confident level of students. Technology integration in education has revealed many benefits to educators and students due to the fact that students are familiar with technology and they will learn better within technology-based environment [11]. Unfortunately, limitation of using technology must be considered. Research by [12] revealed that technical problems become a major barrier for educators for instance, low connectivity, virus attack, LCD and computer not functioning. In addition, students will be exposed to the risk of becoming tech-addicts which has been serious global issue [13]. Another point is lack of supervision from educators will causes students turn to other webpage to browse unrelated topics or inappropriate contents.

Recently, young learners like to use gadgets such as smartphone and tablets to search for diverse information. Consequently, a well-known online application that can be accessed by the gadgets, such as Kahoot which is known as game-based learning that involves student in problem solving, critical thinking and review of content knowledge [14]. Additionally, Kahoot is a platform for impromptu quizzes, discussion and surveys [15]. Although Kahoot helped in learning process, but it is not suitable for mathematics education since learning mathematics is doing calculation and it takes more than 30 seconds for the students to solve the questions.

Based on the above reasons, this study is done to investigate the effectiveness of using CCMPedia in teaching and learning Calculus 1 to all students taking Calculus 1 in the current semester. The CCMPedia is a hardcopy encyclopedia of common calculus mistakes. It special features is very handy which means, easy to carry anywhere and bring in the classroom. The educators and students will not have to worry on the problems that may occur from the technology. CCMPedia was designed by a group of educators from UiTMJ who are currently teaching Calculus 1. In this paper, we aim to examine the effects of time factors and group effects of CCMPedia.

\section{Method}

In this research, a group of 88 students was involved. The students' sample were all from part three Diploma Science Mathematics' students. There were only 4 groups in Semester December 2016 April 2017 that consisted of 22 students each. The sample of group was randomly selected by using random method based on the group of classes and by separating them into control and experimental groups. Two groups were for control group and another two groups were for experimental group. Both groups were homogeneous since they were same semesters and same qualifications entries.

Both groups were given a set of pre-test questions that consisted of three criteria: Basic knowledge of mathematical concepts, Mathematics pre-knowledge from previous education levels, and calculus knowledge. The pre-test examination was conducted in the first week before learning Calculus I. The results of this set were then taken as pre-test scores. After 14 weeks of lecture, the students once again were given a set of same question of post-test questions. Then, the scores were compared to pre-test score. Addition to that, the control group did not apply CCMPedia throughout the 14 weeks of lecture while for the experimental group, CCMPedia has been applied in teaching and learning process for the whole semesters. The score for pre-test and post-test were analyzed by using Mixed Design Analysis.

The questions were set based on the three criteria to investigate students' understanding on Calculus. According to [16], the students' perception or understanding of some calculus topics has always been wrong since they were in secondary schools. They usually tend to carry out the wrong perceptions of conceptional in Calculus to the tertiary level. This research aims to measure the 
effectiveness of CCMPedia in Calculus I in the topics of functions, limit and continuity, differentiation as well as integration.

The analysis to measure the effectiveness was done by using Mixed Design analysis. Mixed Design analysis was used to access the effect of time factors (i.e. Pre-test vs. Post Test), and the group effects (i.e. Experiment vs. Control).

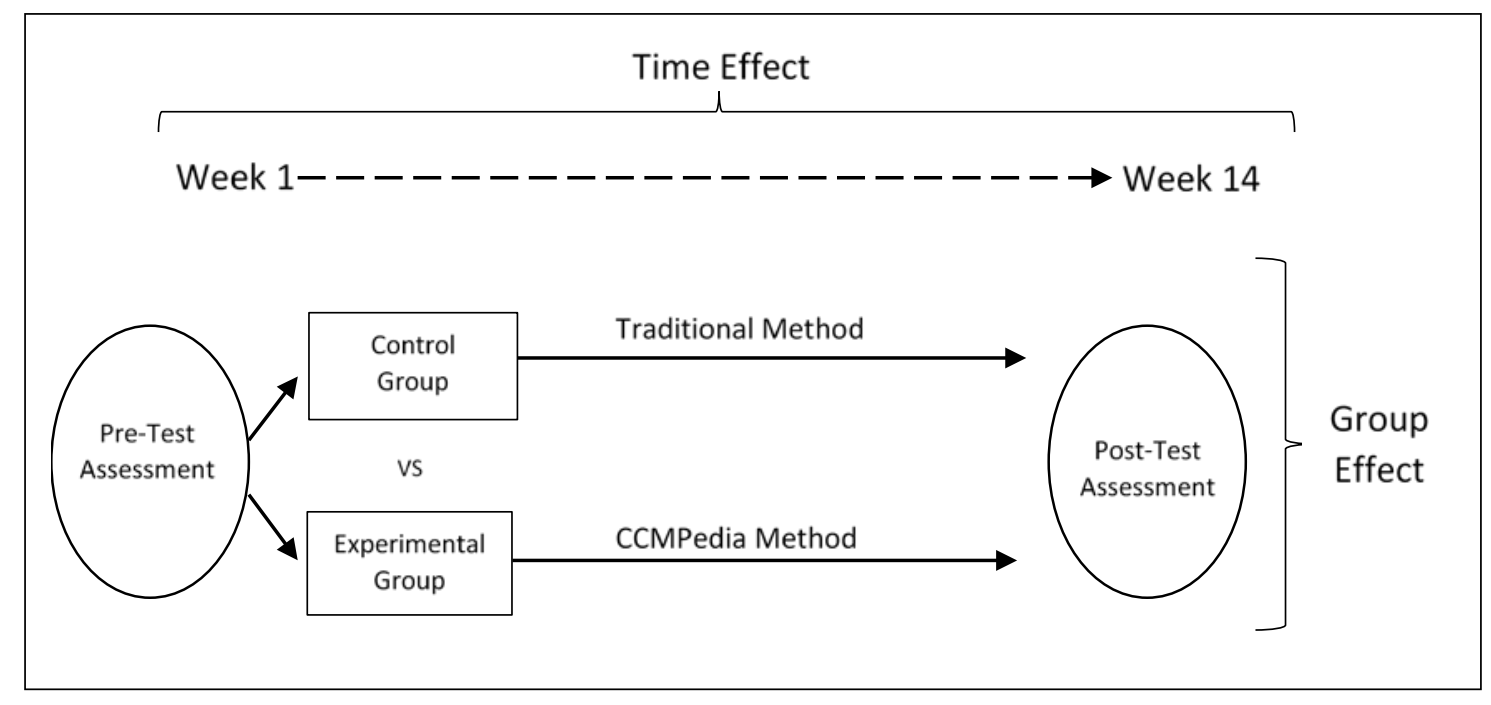

Fig. 1: Research Design

\section{Analysis and Results}

Table 1 shows the results of the descriptive analysis for the three targeted variables based on experimental and control groups. The analysis indicated that, generally there is increasing marks for all targeted variables (i.e. Basic Knowledge, Pre Knowledge, and Calculus 1) from pre-test to post-test, except for Pre Knowledge score for control group (Pre-test: 0.77 \pm 0.71 ; Post-test: $0.73 \pm$ 0.71), where it shows a marginally decreases.

Table 1: Descriptive Analysis based on Groups

\begin{tabular}{|l|c|c|c|c|}
\hline \multirow{2}{*}{ Variable } & \multicolumn{2}{|c|}{ Experiment Group (n=44) } & \multicolumn{2}{|c|}{ Control Group (n =44) } \\
\cline { 2 - 5 } & $\begin{array}{c}\text { Pre-test } \\
(\mathrm{M} \pm \mathrm{SD})\end{array}$ & $\begin{array}{c}\text { Post-test } \\
(\mathrm{M} \pm \mathrm{SD})\end{array}$ & Pre-test $(\mathrm{M} \pm \mathrm{SD})$ & Post-test (M \pm SD) \\
\hline Basic Knowledge & $11.48 \pm 1.52$ & $11.80 \pm 1.46$ & $10.05 \pm 2.54$ & $11.30 \pm 1.71$ \\
\hline Pre Knowledge & $2.16 \pm 0.94$ & $2.55 \pm 0.76$ & $0.77 \pm 0.71$ & $0.73 \pm 0.71$ \\
\hline Calculus 1 & $3.34 \pm 1.16$ & $4.41 \pm 0.87$ & $0.70 \pm 0.85$ & $0.91 \pm 0.81$ \\
\hline
\end{tabular}

Note: $\mathrm{M}=$ Mean; $\mathrm{SD}=$ Standard Deviation.

Mixed Design analysis was used to access the effect of time factors (i.e. Pre-test vs. Post Test), and also the group effects (i.e. Experiment vs. Control) as well as interaction between time and groups effects $[17,18]$. Since this study involve three targeted variables (i.e. Basic Knowledge, Pre Knowledge, and Calculus 1), three mixed design analysis were performed.

According to Montgomery and Field, variables data can approximately normally distributed if the sample size were above 30 samples by using the Central Limit Theorem assessment $[19,17]$. Hence, it can be ensured that, the data distribution for this study was approximately normally distributed since the sample size for each group was 44 samples. Furthermore, mixed design analysis actually robust toward normality assumptions since the fundamental analysis of the mixed design analysis is about Analysis of Variance (i.e. ANOVA) analysis [19].

On the other hand, the issues of sphericity in this analysis was not existed, since the repeated measures (i.e. time factors effect) in this analysis was at the two levels. According to [17] the assessment of sphericity should be considered when the time factor effects were the least at the three levels. In terms of covariance equality, Box' Test was used to access the equality of covariance matrix $[19,17]$. However, mixed design analysis can be considered robust toward this effect if the number of 
samples for both groups is equal [17]. Since, in this analysis both groups were having an equal sample size (i.e. 44 samples for each group), it can be ensured that result of this analysis was valid.

\section{Basic Knowledge Assessment}

A mixed between within subject analysis of variance was conducted to assess the impact of pre-test and post-test scores on Basic Knowledge across Experiment and Control groups was reported in Table 2. The results indicated that, there is significant time effects of Basic Knowledge score $(F(1,86)$ $=12.514, \mathrm{p}<.01$; Effect Size $=.127$ ). It is indicated that, there is statistically increase of Basic Knowledge scores from the pre-test to the post test.

Table 2: Summary Results of Mixed Design Analysis based on Basic Knowledge Scores

\begin{tabular}{|c|c|c|c|c|}
\hline Effect Terms & F Statistics & p-value & Effect Size & Remark \\
\hline${ }^{\mathrm{a}}$ Time Effect & $12.514(1,86)$ & $<.01$ & .127 & Moderate \\
\hline${ }^{\mathrm{b}}$ Group Effect & $8.668(1,86)$ & $<.01$ & .092 & Small \\
\hline${ }^{\mathrm{a}}$ Time* Group Effect & $4.419(1,86)$ & $<.05$ & .049 & Small \\
\hline
\end{tabular}

Note: Time Effect $=$ Pre-test vs. Post Test; Group Effect $=$ Experiment vs. Control; Time*Group Effect $=$ Interaction

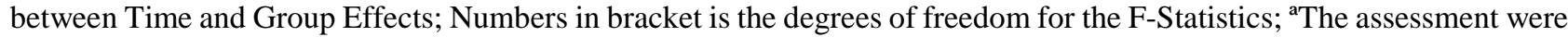
based on Tests of Within-Subjects Effects; ${ }^{b}$ The assessment was based on Between-Subjects Effects.

Besides that, the results also indicated that, there is significant different between Basic Knowledge score between experiment and control groups $(\mathrm{F}(1,86)=8.668, \mathrm{p}<.01$; Effect Size $=.092)$. It is indicated that, the Basic Knowledge scores for the experiment group is higher than control group. In terms of interaction effect, the analysis indicated that, there is also significant effect between time and group effects simultaneously $(\mathrm{F}(1,86)=4.419, \mathrm{p}<.05$; Effect Size $=.049)$. It is indicated that, Basic Knowledge scores were statistically increase from the pre-test to post-test for the both groups, but in the same way, Basic Knowledge scores also statistically differ between experiment and control groups. The effect sizes for the group effect and interaction effect analysis can be considered as small effects, whereas time effect analysis can be considered as moderate effects [20]. Fig. 2 shows the linear plot of pre-test to post-test assessment across the experiment and control groups for the Basic Knowledge scores.

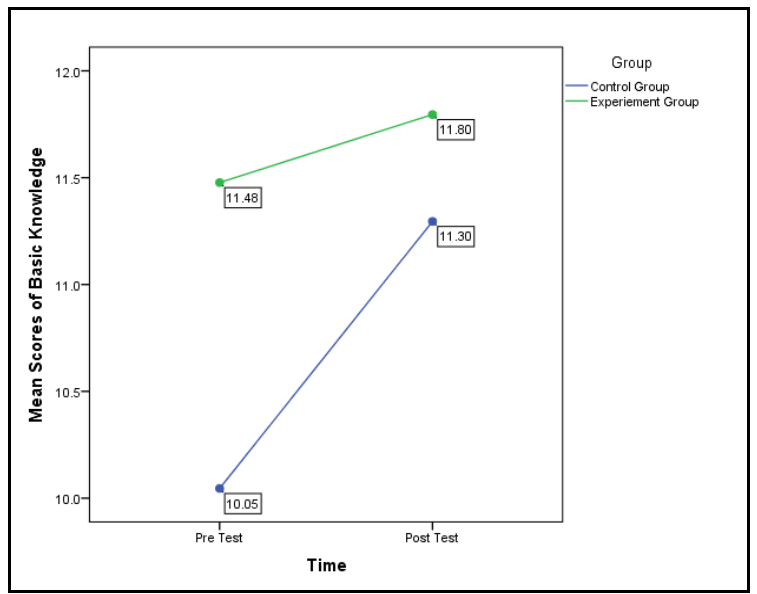

Fig. 2: Linear plot of Pre-test to Post-test assessment across Experiment and Control Groups for Basic Knowledge Score

\section{Pre Knowledge Assessment}

By using the same analysis, Table 3 shows the results of mixed design analysis of variance for assessing the impact of pre-test and post-test scores on Pre Knowledge across Experiment and Control groups. The results indicated that, there is significant time effects at the $90 \%$ confidence level of Pre Knowledge score $(F(1,86)=3.418, \mathrm{p}=.068$; Effect Size $=.038)$. It is indicated that, there is statistically increase of Pre Knowledge scores from the pre-test to the post test. Besides that, the results also indicated that, there is significant different between Pre Knowledge score between experiment and control groups $(\mathrm{F}(1,86)=129.390, \mathrm{p}<.01$; Effect Size $=.601)$. It is indicated that, the Pre Knowledge scores for the experiment group is higher than control group. 
Table 3: Summary Results of Mixed Design Analysis based on Pre Knowledge Scores

\begin{tabular}{|c|c|c|c|c|}
\hline Effect Terms & F Statistics & p-value & Effect Size & Remark \\
\hline${ }^{\mathrm{a}}$ Time Effect & $3.418(1,86)$ & $<.10$ & .038 & Small \\
\hline${ }^{\mathrm{b}}$ Group Effect & $129.390(1,86)$ & $<.01$ & .601 & Large \\
\hline${ }^{\mathrm{a}}$ Time*Group Effect & $5.483(1,86)$ & $<.05$ & .060 & Small \\
\hline
\end{tabular}

Note: Time Effect = Pre-test vs. Post Test; Group Effect $=$ Experiment vs. Control; Time*Group Effect $=$ Interaction

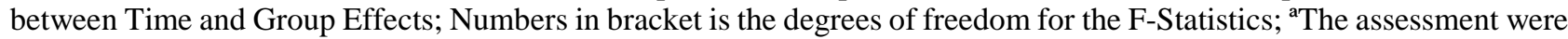

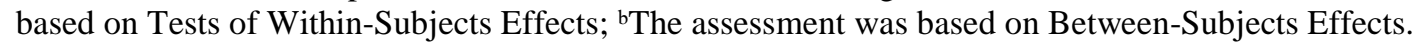

In terms of interaction effect, the analysis indicated that, there is also significant effect between time and group effects simultaneously $(\mathrm{F}(1,86)=5.483$, $\mathrm{p}<.05$; Effect Size $=.060)$. It is indicated that, Pre Knowledge scores were statistically increase from the pre-test to post-test for the experiment group except for the control group, but in the same way, Pre Knowledge scores also statistically differ between experiment and control groups. The effect sizes for the time effect and interaction effect analysis can be considered as small effects, whereas group effect analysis can be considered as large effects [20]. Fig. 3 shows the linear plot of pre-test to post-test assessment across the experiment and control groups for the Pre Knowledge scores.

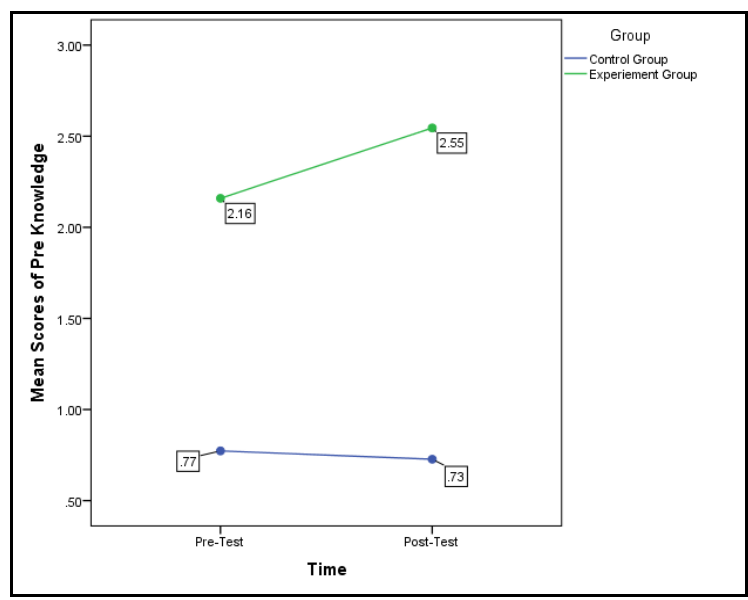

Fig. 3: Linear plot of Pre-test to Post-test assessment across Experiment and Control Groups for Pre Knowledge Scores

\section{Calculus 1 Assessment}

Table 4 shows the results of mixed design analysis of variance for assessing the impact of pre-test and post-test scores on Calculus 1 across Experiment and Control groups. The results indicated that, there is significant time effects of Calculus 1 score $(F(1,86)=25.982$, $p<.01$; Effect Size $=.232)$. It is indicated that, there is statistically increase of Calculus 1 scores from the pre-test to the post test. Besides that, the results also indicated that, there is significant different between Calculus 1 score between experiment and control groups $(\mathrm{F}(1,86)=362.226, \mathrm{p}<.01$; Effect Size $=.808)$. It is indicated that, the Calculus 1 scores for the experiment group is higher than control group.

Table 4: Summary Results of Mixed Design Analysis based on Calculus 1 Scores

\begin{tabular}{|c|c|c|c|c|}
\hline Effect Terms & F Statistics & p-value & Effect Size & Remark \\
\hline${ }^{\text {a}}$ Time Effect & $25.982(1,86)$ & $<.01$ & .232 & Moderate \\
\hline${ }^{\text {b} G r o u p ~ E f f e c t ~}$ & $362.226(1,86)$ & $<.01$ & .808 & Large \\
\hline $\begin{array}{c}\text { Time*Group } \\
\text { Effect }\end{array}$ & $11.964(1,86)$ & $<.01$ & .122 & Moderate \\
\hline
\end{tabular}

Note: Time Effect = Pre-test vs. Post Test; Group Effect $=$ Experiment vs. Control; Time*Group Effect = Interaction between Time and Group Effects; Numbers in bracket is the degrees of freedom for the F-Statistics; ${ }^{a}$ The assessment were based on Tests of Within-Subjects Effects; ${ }^{\text {b The assessment }}$ was based on Between-Subjects Effects. 
In terms of interaction effect, the analysis indicated that, there is also significant effect between time and group effects simultaneously $(\mathrm{F}(1,86)=11.964, \mathrm{p}<.01$; Effect Size $=.122)$. It is indicated that, Calculus 1scores were statistically increase from the pre-test to post-test for the both groups, but in the same way, Calculus 1 scores also statistically differ between experiment and control groups. The effect sizes for the time effect and interaction effect analysis can be considered as moderate effects, whereas group effect analysis can be considered as large effects [20]. Fig. 4 shows the linear plot of pre-test to post-test assessment across the experiment and control groups for the Calculus 1 scores.

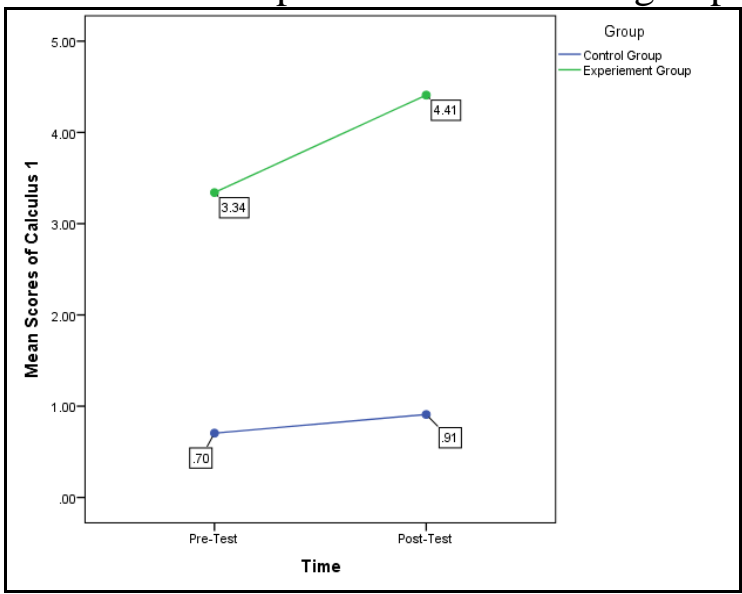

Fig. 4: Linear plot of Pre-test to Post-test assessment across Experiment and Control Groups for Calculus 1 Scores

\section{Discussion and Conclusion}

In this research, CCMPedia has been applied for the experimental group through out the 14 weeks of lecture while for the control group, traditional method without using CCMPedia was used in teaching and learning process. After 14 weeks of lecture, both groups were given a set of post-tests. The score for both groups were then analyzed and seperated into three criteria: Basic Knowledge, Pre-Knowledge and Calculus 1. From the results, for the Pre-Knowledge and Calculus 1 assessments, the use of CCMpedia is very helpful in teaching and learning because of the group effect size is large which is 0.601 and 0.808 respectively. The results show significantly increase for both assessments. This shows that, using CCMPedia in classes will reduce the mistakes done by the students and they have better understanding in that particular topics. While for Basic Knowledge, the use of CCMPedia is not really helpful but it still significant increases statistically (with 0.092 group effect size).

The finding indicates that CCMPedia is one of the good mechanisms to assist students in learning process especially in basic knowledge and Calculus I. However, CCMPedia is also useful tool to increase students' understanding in basic knowledge. CCMPedia gives a positive results for experimental group where the increments of students knowledge are clearly seen in the time effect size for all three categories. CCMPedia is a new and has special criteria that are easy to use in searching information and references. It helps students to make less common mistakes while doing Calculus 1 . The implementation of CCMPedia will result in easier teaching and learning process, not only for UiTM students but for other students in other universities as well. As a recommendation, it is suggested that future researches to measure the effectiveness of CCMpedia in teaching and learning Calculus for non-mathematics students.

\section{Acknowledgement}

The authors would like to thank Universiti Teknologi MARA (UiTM) and Institute of Research Management and Innovation (IRMI) of UiTM in providing the Academic and Research Assimilation research grant, code 600-IRMI/DANA 5/3/ARAS (0085/2016). 


\section{References}

[1] Sarwadi, R. and Shahrill, M. (2014). Understanding Students' Mathematical Errors and Misconceptions: The Case of Year 11 Repeating Students, Mathematics Education Trends and Research, 2014: 1-10

[2] Thomas, M. O. J., De Freitas Druck, I., Huillet, D., Ju, M. K., Nardi, E., Rasmussen, C. and Xie, J. (2012) Key mathematical concepts in the transition from secondary to university. In: Pre-proceedings of the 12th international congress on mathematical education (ICME-12) Survey Team 4, pp 90-136, Seoul

[3] C.J. Bonk and D.J. Cunningham, Searching for learner-centered, constructivist, and sociocultural components of collaborative educational learning tools, Indiana University,

[4] Borko, H., Jacobs, J., Eiteljorg, Eric., \& Pittman, M. E. (2008). Video as a tool for fostering productive discussions in mathematics professional development. Teaching and Teacher Education. Volume 24, Issue 2, February 2008, Pages 417-436

[5] Lajoie S. P. \& Lavigne, N.C. (2017). Mathematics-Learning-Learning-Tools, page 2202 retrieved from http://education.stateuniversity.com/

[6] Ahmad. S. N., Mahadi. S., Yusri. M.Y., Yusop. H., Ali. M. N., \& Heng. C.H. (2017). Factors Related to Students' Performance in Calculus. Journal of Applied Environmental and Biological Sciences, 7(6S), 51-56, ISSN:2090-4274

[7] Ghavifekr, S., Abd Razak, A.Z., Ghani, M.F.A., Ran, N.Y., Meixi, Y. \& Tengyue, Z. (2014). ICT Integration In Education: Incorporation for Teaching \& Learning Improvement. Malaysian Online Journal of Educational Technology (MOJET),2 (2), 24-46.

[8] Lynch, M. (2017). 10 virtual tools for the maths classroom. Retrieved from http://www.thetechedvocate.org/edtech-tools/

[9] Duska, P. \& Aleksandar, P. (2015). The use of visual approach in teaching and learning the epsilondelta definition of continuity. European Journal of Science and Mathematics Education Vol. 3, No. 3, 2015, 205-218

[10] Lin, A. (2012). Eyes on Math: A visual approach to Teaching Math Concepts. Retrived from https://amylin.me/2012/11/27/eyes-on-math-a-visual-approach-2/

[11] Ghavifekr, S. \& Wan Athirah, W. R. (2015). Teaching and Learning with Technology: Effectiveness of ICT Integration in Schools. International Journal of Research in Education and Science, 1(2), 175-191.

[12] Türel, Y. K., \& Johnson, T. E. (2012). Teachers' Belief and Use of Interactive Whiteboards for Teaching and Learning. Educational Technology \& Society, 15(1), 381-394

Wiley and Sons Publications.

[13] Muduli, J. R.(2014). Addiction to technological gadgets and its impact oh health and lifestyle: a study on college students. MA Thesis. Retrieved from ethesis.nitrkl.ac.in

[14] Dellos, R. (2015). Kahoot! A digital game reseource for learning. International Journal of Instructional Technology and Distance Learning, Vol 12, no 4, page 49, ISSN 1550-6908

[15] Byrne, R. (2013). Free technology for teachers: Kahoot! - create quizzes and surveys your students can answer on any device. Retrieved from http://www.freetech4teachers.com/2013/11/kahoot-create-quizzes-and-surveysyour.html\#.VLnc78b uzuU 
[16] Petocz, P., Reid, A., Wood, L. N., Smith, G. H., Mather, G., Harding, A., Engelbrecht, J., Houston, K., Hillel, J., \& Perrett, G. (2007). Undergraduate Students' Conceptions of Mathematics: An International Study. International Journal of Science and Mathematics Education (2007)5, 439-459.

[17] Field, A. (2009). Discovering Statistics Using SPSS (3rd Edition). London: SAGE Publications [18] Pallant, J (2010). SPSS Survival Manual (4th Edition). New York: McGraw-Hill Publications. [19] Montgomery, D.C. (2009). Design and Analysis of Experiments ( $7^{\text {th }}$ edition). New York: John Wiley and Sons Publications.

[20] Cohen, J.W. (1988). Statistical Power Analysis for the Behavioral Sciences (2nd Edition). Hillsdale, NJ: Lawrance Erlbaum Assocaites. 